\title{
Tip 1 Diyabetes Mellitus Tanılı Pediatrik Nekrobiyozis Lipoidika Olgusu
}

\author{
A Case of Pediatric Necrobiosis Lipoidica Diagnosed with Type 1 Diabetes Mellitus
}

\section{${ }^{1}$ Dilara Güler, ${ }^{1}$ Gülhan Gürel , ${ }^{2}$ Çiğdem Özdemir}

${ }^{1}$ Afyonkarahisar Sağlık Bilimleri Üniversitesi, Dermatoloji Anabilim Dalı, Afyonkarahisar, Türkiye

${ }^{2}$ Afyonkarahisar Sağlık Bilimleri Üniversitesi, Patoloji Anabilim Dalı, Afyonkarahisar, Türkiye

\section{Özet}

Nekrobiyozis lipoidika, etyolojisi ve patogenezi henüz net olarak bilinmeyen granülomatöz bir deri hastalı̆̆ıdır. Diyabetes mellitus ve nekrobiyozis lipoidika komorbiditesi literatürde sıkça tartışılmakta olup mikroanjiyopatinin bu komorbiditede önemli bir role sahip olduğu düșünülmektedir. Nekrobiyozis lipoidika, diyabetes mellitus ile eş zamanlı ortaya çıabilmekle beraber diyabetes mellitus tanısından önce veya sonra da ortaya çıkabilmektedir. Nekrobiyozis lipoidikanın kanıtlanmış etkin bir tedavisi bulunmamaktadır. Köbnerizasyon nedeniyle cerrahi tedavi önerilmemektedir. Burada yaklaşık 2 yıldır her iki alt ekstremitede multiple lez yonları olan ve yapılan punch biyopsi ile histopatolojik olarak nekrobiyozis lipoidika tanısı konulan 15 yaşında kız hasta sunuldu. Olgumuz ile nekrobiyozis lipoidika etyolojisi, kliniği ve tedavisi literatür ışığında değerlendirildi.

Anahtar Kelimeler: Nekrobiyozis lipoidika; Diyabetes mellitus; Pediatrik; Deri

\section{Abstract}

\begin{abstract}
Necrobiosis lipoidica is a granulomatous skin disease of unknown etiology and pathogenesis. The comorbidity of diabetes mellitus and necrobiosis lipoidica is frequently discussed in the literature and it is thought that microangiopathy has an important role in this comorbidity. Although necrobiosis lipoidica may occur at the same time as diabetes mellitus, it may occur before or after the diagnosis of diabetes mellitus. There is no proven effective treatment for necrobiosis lipoidica. Surgical treatment is not recommended due to koebnerization. Here, we present a 15-year-old female patient who had multiple lesions in both lower extremities for about 2 years and was diagnosed histopathologically with necrobiosis lipoidica by punch biopsy. In this case report, the etiology, clinic and treatment of necrobiosis lipoidica were evaluated in the light of the literature.
\end{abstract}

Keywords: Necrobiosis lipoidica; Diyabetes mellitus; Pediatric; Skin 


\section{Giriş}

Nekrobiyozis lipoidika (NL), klasik olarak diyabetik kişilerde ortaya çıkan, ülserasyon riski taşıyan, nadir görülen, kronik, idiyopatik, kollajen dejenerasyonu ile karakterize bir granülomatöz hastalıktır. NL'nin etyolojisi net olarak bilinmemektedir. Kollajen dejenerasyonunun immun kompleks birikimi ve mikroanjiopatik değişikliklerden kaynaklandığ düşünülmektedir (1).

Diyabetli bireylerde artan bir prevalansina rağmen, bu hastalarda NL görülme sıklığı sadece $\% 0,3$ - \% 1,2'dir (2). NL, \% 14 hastada diyabetes mellitus (DM) tanısından önce ortaya çıkarken, \% 24 hastada DM ile eşzamanlı olarak ortaya çıkmaktadır. Vakaların \% 62'sinde ise DM teşhisi konulduktan sonra ortaya çıkmaktadır. Glisemik kontrol seviyesi ile NL geliştirme olasılığ arasında kanıtlanmış bir ilişki yoktur. Altta yatan herhangi bir hastalığı olmayan sağlıklı bireylerde görülebilse de, yaygın olarak eşlik ettiği diğer durumlar; tiroid bozuklukları ve Crohn hastalığı, ülseratif kolit, romatoid artrit ve sarkoidoz gibi inflamatuar hastalıklardır. Kadınlarda daha s1k görülmektedir (2).

Klasik lezyonlar, alt bacakların ön yüzünde ortaya çıkan, merkezi atrofik, oval veya düzensiz sert plaklardır. Kadınlarda daha yaygındır ve genellikle genç veya orta yetişkinlikte ortaya çıkmaktadır (3). Burada tibiada bilateral yerleşimli NL lezyonu olan pediatrik bir olgu sunulmaktadır.

\section{Olgu}

15 yaşında kız hasta 2 yıldır olan her iki bacak ön yüzdeki lezyonları nedeniyle polikliniğimize başvurdu. Hastanın özgeçmişinden Tip 1 DM tanısıyla insülin pompası tedavisi almakta olduğu öğrenildi. Hastanın soygeçmişinde özellik yoktu. Hastanın dermatolojik muayenesinde her iki tibia ön yüzde ve sağ ayak dorsolateralinde kenarları viyolese renkte belirgin, ortası sarı kahverengi atrofik telenjiektatik 6 adet plak lezyon izlendi (Resim 1). Hastanın sistemik muayenesi doğaldı. Hastanın tam kan sayımı, karaciğer ve böbrek fonksiyon testleri normaldi, Borrelia antikorları negatifti ve tokluk kan şekeri $436 \mathrm{mg} / \mathrm{dl}$ idi. Hastanın mevcut lezyonlarından nekrobiozis lipoidika, morfea, likenskleroatrofikus, sarkoidoz ve granuloma anulare ön tanilariyla punch biyopsi alınd1. Histopatolojik incelemede epidermis düzenli yapıda, üst dermiste histiyositten zengin bir inflamasyon, orta dermiste nekroz ve çevresinde multinukleer dev hücreler izlendi (Resim 2). Mevcut klinik ve histopatolojik bulgularla NL tanis1 konularak topikal klobetazol propionat merhem haftada 3 gün kullanılması önerildi. 3 ay sonraki kontrol muayenesinde lezyonlarda kısmi gerileme izlendi. Kısmi gerileme olan lezyonlar için hastaya diğer tedavi seçenekleri sunuldu ancak hasta diğer tedavileri reddetti. Hasta halen takibimiz altındadır.

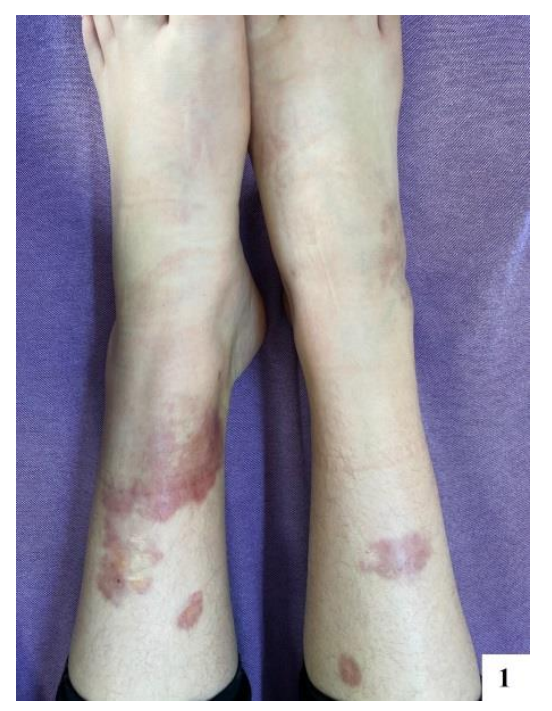


Resim 1. Her iki tibia ön yüzde ve să̆ ayak dorsolateralinde izlenen kenarları viyolese renkte, belirgin, ortası sarı kahverengi atrofik telenjiektatik plak lezyonlar

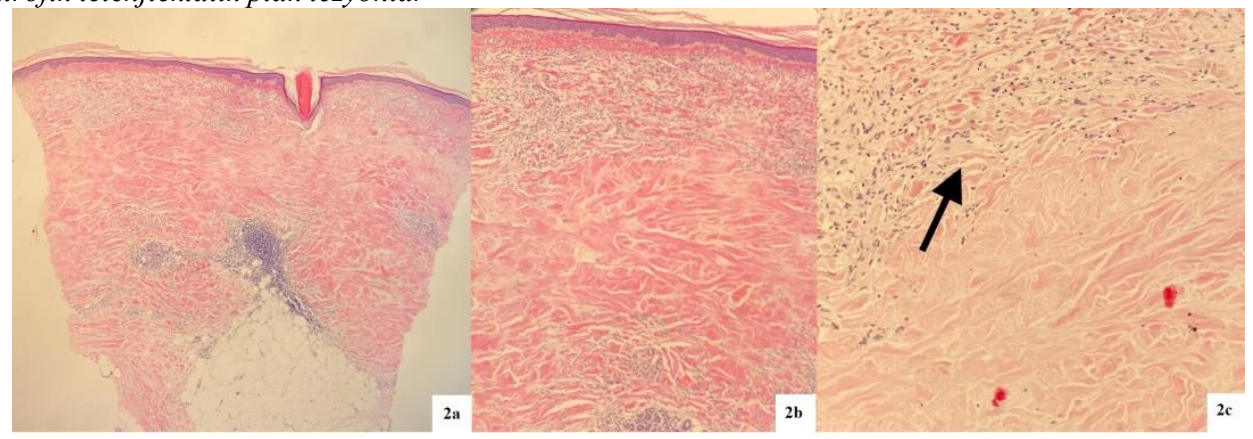

Resim 2. 2a: Orta dermişteki nekrozu çevreleyen üst dermişte histiositlerden oluşan inflamasyon, derin dermişte yer yer yoğunlaşan lenfositik iltihabi hücre infiltrasyonu $(x 40 \mathrm{HE})$. 2b: Orta dermşste geniş nekroz alanı ve çevresinde histiositlerden oluşan reaktif inflamasyon (x100 HE). 2c: Nekroz çevresinde multinukleer dev hücre reaksiyonu (ok) (x200 $H E)$.

\section{Tartışma ve Sonuç}

NL, tipik olarak pretibial bölgede yerleșen, viyolese keskin sınırlı, sarı-kahverengi, merkezi mumsu atrofik görünümde, telanjiektatik plaklarla karakterizedir. Daha az siklıkta, üst ekstremiteler, yüz ve skalpta yerleşebilmektedir. Lezyonlar genellikle küçük, sert, kırmız1kahverengi papüller şeklinde başlayıp yavaş yavaş genişler ve ardından merkezi epidermal atrofi gelişir. Ülserasyon lezyonların yaklaşık üçte birinde, genellikle minör travmayı takiben ortaya çıkar. Plaklar genellikle çok sayıda ve çift taraflıdır. $\mathrm{Bu}$ lezyonlar travmatize edilirse köbnerize olabilir. Bu nedenle, cerrahi tedaviler önerilmez $(2,4)$. Ülserleşme erkeklerin \% 58' inde, kadınların \% $15^{\prime}$ inde bildirilmiştir (2). Erkek hastalarda NL lezyonlarında ülserleşme olasılığı daha yüksek olduğu için hastalık erkeklerde daha şiddetli seyretme eğilimindedir. NL plaklarında iğne batması ve ince dokunma hissinde azalma, hipohidroz ve parsiyel alopesi görülebilir. NL lezyonları üzerinden gelişen skuamöz hücreli karsinomlu vaka bildirimleri mevcuttur $(2,4)$.

Tanı genellikle klinik muayeneye dayanmasına rağmen, NL'yi granuloma anulare ve necrobiyotik ksantogranuloma dahil benzer klinik görünümlere sahip durumlardan ayırmak için biyopsi yapılmalidır. Histopatolojide, subkutan doku ve dermiste interstisyel alanda palizadlanmış nekrobiyotik granülomlar izlenmektedir. Uzun süreli lezyonlarda, kollajen dejenerasyonu belirgin hale gelmekte, dermis ve subkutan yağ dokusu tabakalı granülomatöz bir görünüm almaktadır. Multinükleer dev hücreler ve lipid damlacıklarının varlığıyla elastik doku kayb1 izlenmektedir. Klinik olarak NL lezyonlarının görünümü diyabetik ve diyabetik olmayan hastalarda aynı olmakla birlikte, histolojik bulgular değişkenlik gösterebilir. Palizadlaşan patern diyabetik hastalarda daha s1k görülmektedir $(1,5,6)$.

Venöz hastalık veya periferik arter hastalı̆̆ 1 şüphesi olan hastalarda, ileri değerlendirmeler yapılmalıdır. Temel laboratuvar tetkikler, DM'yi taramak veya DM tanılı hastalarda kan şekeri kontrolünü değerlendirmek için açlık kan şekeri veya glikozile edilmiş hemoglobini içermelidir. Bunlar tanısal değilse, NL diyabetin ilk bulgusu olarak ortaya çıkabildiğinden tetkikler her yıl tekrarlanmalidır (2). Olgumuzun 5 yıldır tip 1 DM tanısı mevcuttu ve yaklaşık 2 yıl önce NL lezyonları ortaya çıkmaya başlamıştı.

NL'nin kanıtlanmış etkin bir tedavisi yoktur. DM'li hastalarda, kan șekerinin kontrolünün hastalık seyri üzerinde önemli bir etkisi gösterilmemiştir. Asemptomatik vakalarda ve ülserasyon izlenmeyen vakalarda, lezyonların yaklaşı \%17'sinin kendiliğinden düzelebileceği göz önüne alındığında, NL tedavisiz bırakılabilir. Kompresyon tedavileri ödemi kontrol etmekte ve ilişkili venöz hastalı̆̆ veya lenfödemi olan hastalarda iyileşmeyi desteklemektedir $(7,8)$. Ülser oluştuğunda, uygun yara bakımı önemlidir. Birinci basamak tedavi, erken lezyonlar için güçlü topikal kortikosteroidlerin kullanımı ve yerleşmiş lezyonların aktif kenarlarına intralezyonel kortikosteroid uygulamalarıdır. İnaktif, atrofik lezyonlarda, atrofiyi şiddetlendirip yeni ülserasyon riskini artırabileceğinden topikal 
steroidlerden kaçınılmalıdır. PUVA, aktif inflamatuar sinırları azaltmaktadır ancak atrofik skarlar üzerinde klinik etkisi bulunmamaktadır. Topikal takrolimusun, NL ile ilişkili ülserlerin tedavisinde etkili olduğu gösterilmiştir (9-11).
Etanersept ve infliksimab da ülsere NL'da monoterapide kullanılan diğer ajanlardır (2). Biz de hastamıza 1. basamakta önerilen tedavi seçeneklerinden olan güçlü topikal steroid tedavisi verdik ve kısmi yanıt aldık.

\section{KAYNAKLAR}

1. Sibbald C, Reid S, Alavi A. Necrobiosis lipoidica. Dermatol Clin. 2015;33:343-60.

2. Lepe K, Salazar FJ. Necrobiosis lipoidica. In: StatPearls. StatPearls Publishing, Treasure Islands. 2020

3. Muller SA, Winkelmann R. Necrobiosis lipoidica diabeticorum: a clinical and pathological investigation of 171 cases. Arch Dermatol. 1966;93:272-81.

4. McBriar D, Costley M, Houghton J, et al. Images of the month: A painful nodule arising within chronic necrobiosis lipoidica. Clin Med. 2020;20:e269.

5. Hawryluk EB, Izikson L, English JC. Noninfectious granulomatous diseases of the skin and their associated systemic diseases. Am $\mathrm{J}$ Clin Dermatol. 2010;11:171-81.

6. Lowitt MH, Dover JS. Necrobiosis lipoidica. J Am Acad Dermatol. 1991;25:735-48.
7. Fertitta L, Vignon-Pennamen M-D, Frazier A, et al. Necrobiosis lipoidica with bone involvement successfully treated with infliximab. Rheumatology. 2019.

8. Hashemi DA, Brown-Joel ZO, Tkachenko E, et al. Clinical features and comorbidities of patients with necrobiosis lipoidica with or without diabetes. JAMA Dermatol. 2019;155:455-9.

9. Imadojemu $\mathrm{S}$, Rosenbach $\mathrm{M}$. Advances in inflammatory granulomatous skin diseases. Dermatol Clin. 2019;37:49-64.

10. Dissemond J, Erfurt-Berge C, Goerge T, et al. Systemic therapies for leg ulcers. $J$ Dtsch Dermatol Ges. 2018;16:873-90.

11. Lause M, Kamboj A, Faith EF. Dermatologic manifestations of endocrine disorders. Transl Pediatr. 2017;6:300. 